\title{
PROPRIEDADES FÍSICAS INDICADORAS DA QUALIDADE DO SOLO SOB SISTEMAS DE MANEJO - ALTA FLORESTA
}

\author{
Juliano Cassio Burgrever ${ }^{1}$, Felipe Fernandes de Freitas ${ }^{1}$, Thainara Aparecida Ferrari Fistarol ${ }^{1}$, Fábio \\ Bezerra de Araújo ${ }^{1}$, Getúlio de Freitas Seben Júnior ${ }^{2}$.
}

${ }^{1}$ Discente na Universidade do Estado de Mato Grosso, Alta Floresta, MT, Brasil. ${ }^{2}$ Docente na Universidade do Estado de Mato Grosso, Alta Floresta, MT Brasil.

RESUMO: A avaliação dos atributos do solo é importante para o entendimento dos impactos da atividade agropecuária sobre a qualidade física do solo. Neste contexto, o estudo avaliou as propriedades físicas do solo sob pastagem (PA), mata nativa $(\mathrm{MN})$ e reflorestamento (RF). Amostras de solo foram coletadas na camada de 0,0 $0,10 \mathrm{~m}$ de profundidade para a determinação da densidade do solo (DS), densidade de partículas (DP), porosidade total (PT), macro (MA) e microporosidade (MI) e índice de estabilidade de agregados em água (IEA). Os dados foram submetidos à análise de variância (Teste F) e, quando significativos, as médias foram comparadas pelo teste Tukey $(\alpha=0,05)$. A PA proporcionou ao solo os maiores valores de $D S$, os menores valores de PT e a MA e não diferiu quanto ao IEA, em comparação ao solo sob MN, mostrando a perda de qualidade com a conversão do uso do solo. A MI não foi afetada pelos sistemas de uso. Portanto, o manejo inadequado das pastagens (correção da acidez do solo, adubação, terraceamento, controle da taxa de lotação, entre outras) leva o solo a reduzir sua qualidade física e potencial produtivo.

Palavras-chave: Compactação do solo, sistemas de uso e manejo do solo, qualidade física do solo, manejo de pastagens no Bioma Amazônico.

\section{SOIL PHYSICAL PROPERTIES AS INDICATOR OF QUALITY UNDER MANAGEMENT SYSTEMS - ALTA FLORESTA}

ABSTRACT: The evaluation of soil properties is important to understanding the impacts of the agricultural activity on soil physical quality. In this context, this study evaluated the soil physical properties under pasture (PA), native forest (NF) and reforestation (RF). Soil samples were collected into 0.0 - $0.10 \mathrm{~m}$ depth layer, to determine soil bulk density (DS), particle density (PD), total porosity (TP), macro (MA) and microporosity (MI) and aggregate water stability index (AWS). The data were submitted to variance analysis (Test $F$ ) and, when it is significant, the averages were compared by Tukey test $(\alpha=0.05)$. Soil under PA had higher DS, lower PT and 
MA and did not differ for WSA, compared to the soil under NF, showing significant losses of soil quality by conversion of NF to PA. Soil MI was not affected by soil use systems. Thus, the inappropriate pasture management (soil acidity correction, fertilization, terracing, stocking rate control, among others) leads the soil to reduce its physical quality and productive potential.

Keywords: Soil compaction, soil use and managment systems, soil physical quality, pasture management at Amazonian Biome.

\section{INTRODUÇÃO}

Os solos da região Amazônica apresentam baixa fertilidade natural (OSTERTAG, 2001) devido às condições climáticas, às características do material de origem e ao relevo, os quais contribuem para a formação de solos profundos e muito intemperizados (LIMA, 2001). Os solos tropicais sob mata nativa, especialmente na Amazônia, vêm sendo constantemente convertidos para sistemas de uso intensivos: pastagens e agricultura, levando alguns solos à degradação severa de seus atributos físicos. Assim, há a necessidade de recuperar a capacidade produtiva destes solos ou estabilizar os processo de degradação para aumentar o potencial econômico e a capacidade de suporte dos solos neste ecossistema (NEVES, 2005).

Para tanto, o monitoramento da qualidade física do solo se faz necessário para o planejamento das práticas conservacionistas de manejo que levam a conservação do solo e da água. A qualidade física refere-se à capacidade que o solo apresenta em sustentar o desenvolvimento das plantas sem que se degrade (LLANILLO et al., 2013) e pode ser avaliada por meio da determinação da densidade do solo, da porosidade, da infiltração de água no solo, da resistência mecânica do solo à penetração e da condutividade hidráulica saturada (INGARAMO, 2003). A degradação do solo reduz a porosidade total, a infiltração de água no solo e, consequentemente, a produtividade das culturas (LOURENTE et al., 2011).

Os sistemas de uso e manejo alteram os atributos físicos do solo, favorecendo sua degradação (LIMA et al., 2003). No bioma Amazônico a degradação do solo é 
decorrente da remoção da vegetação nativa e da incorporação da serapilheira que protegiam o solo contra as intempéries climáticas e à erosão. Além disso o revolvimento intenso para a instalação das pastagens causa a quebra da estrutura do solo e disponibiliiza a matéria orgânica à degradação microbiana, deixando de atuar na agregação dos solos juntamente com a gibbsita (hidróxidos de Al). Outra causa da degradação dos solos é o adensamento, que reduz a permeabilidade da água no solo, reduz as trocas gasosas e até mesmo restringe o desenvolvimento do sistema radicular das plantas cultivadas.

Portanto, vale ressaltar a importância da vegetação nativa, de áreas de reflorestamento e até mesmo de pastagens bem manejadas (calagem, adubação, terraceamento, controle de taxa de lotação, entre outras) para a manutenção da qualidade do solo, para a filtragem de sedimentos e compostos químicos, para a percolação de água e dinâmica de gases, para o incremento de materia orgânica, entre outros. Neste contexto, as avaliações das alterações promovidas pelos sistemas de manejo tornam-se importantes para o entendimento das potencialidades e das limitações de uso dos solos. Assim, o presente estudo objetivou quantificar as alterações das propriedades físicas do solo, sob sistemas de uso e manejo de um solo tropical contido no Bioma Amazônico.

O estudo foi realizado em uma propriedade denominada de Piscicultura Esteio, situada no município de Alta Floresta, MT. O solo foi classificado como Latossolo Vermelho-Amarelo distrófico, segundo os critérios estabelecidos pela Embrapa (2013). O clima é classificado como Aw (Clima Tropical) de acordo com classificação (KÖPPEN-GEIGER). A temperatura média anual é de $25,4{ }^{\circ} \mathrm{C}$ e a pluviosidade média de $2.281 \mathrm{~mm}$, concentrada entre os meses de outubro e março (CLIMATEDATA.ORG).

As amostras de solo foram coletadas no mês de julho de 2017 nos seguintes sistemas de uso e manejo do solo: 
a) Pastagem: Pastagem contínua de Brachiaria brizantha, implantada em 1980, sem a realização da correção da acidez do solo e de adubações de manutenção.

b) Mata nativa: remanescente de Floresta Amazônica, sem ação antrópica.

c) Reflorestamento: Área implantada entre os anos de 1985 e 1987 com espécies diversas, envolvendo frutíferas e nativas do bioma amazônico.

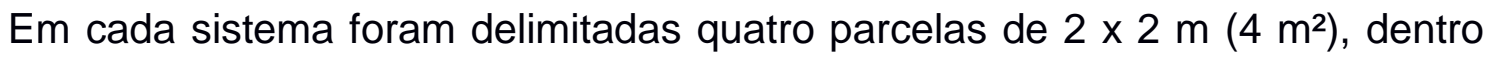
das quais foram coletadas, aleatoriamente, amostras indeformadas de solo, na camada de 0,0-0,10 $\mathrm{m}$ de profundidade, utilizado anéis volumétricos em aço com 5 $\mathrm{cm}$ de altura e $5 \mathrm{~cm}$ de diâmetro, para a determinação da densidade de solo, densidade de partícula, porosidade total, macro e microporosidade (EMBRAPA, 1997). Foram coletadas, ainda, amostras indeformadas, com o uso de enxadão, para separação de agregados com tamanho entre 2,00 e 1,00 mm para a determinação do índice de estabilidade de agregados em água (Yoder, 1936). Para tal foram pesadas $10 \mathrm{~g}$ de agregados secos ao ar e colocados por três minutos sobre uma peneira com abertura de malha de $250 \mu \mathrm{m}$ submetida à agitação vertical em água, a 31 ciclos $\min ^{-1}$ e amplitude de oscilação de cinco centímetros. O material de solo retido na peneira foi levado à estufa a $105^{\circ} \mathrm{C}$ até atingir peso constante e, posteriormente, determinado a porcentagem de agregados estáveis. .

Os resultados foram submetidos à análise de variância pelo Teste $\mathrm{F}$ e, quando significativos, as médias foram comparadas pelo teste Tukey $(\alpha=0,05)$, utilizando o programa estatístico SISVAR 5.6 ( (FERREIRA, 2008).

Na comparação de médias de tratamentos são utilizadas, no corpo da tabela, na coluna ou na linha, à direita do dado, letras minúsculas ou maiúsculas, com a indicação em nota-de-rodapé do teste utilizado e a probabilidade. Para indicação de significância estatística, são utilizadas, no corpo da tabela, na forma de expoente, à direita do dado, as chamadas ns (não-significativo); ${ }^{*} e^{* *}$ (significativo a 5 e $1 \%$ de probabilidade, respectivamente). 


\section{RESULTADOS}

A pastagem incrementou a densidade do solo, reduziu a porosidade total e a macroporosidade em comparação à mata nativa, mas ambos não diferiram do reflorestamento quanto a densidade e porosidade total (Tabela 1). Estes resultados podem ser atribuidos ao pisoteio animal sobre o solo com uma baixa quantidade de resíduos vegetais necessários para amenizar o tráfego animal.

Os sistemas de manejo não proporcionaram diferenças sobre os microporos, contudo, o reflorestamento apresentou valores de macroporosidade semelhantes ao solo sob mata nativa, indicando que o reflorestamento está recuperando a qualidade física do solo após sua adoção em solos degradados, por meio da renovação do sistema radicular das espécies arbóreas.

Embora o solo sob pastagem tenha apresentado valores de agregação semelhantes à mata nativa e ambos maiores que o reflorestamento, este valor de índice de estabilidade de agregados sob pastagem pode ser atribuído ao adensamento das partículas do solo e não a presença de agentes cimentantes, como a matéria orgânica, que provavelmente esteja em teores mais elevados no solo sob mata nativa.

Tabela 1. Atributos físicos e um Latossolo Vermelho-amarelo distrófico sob mata nativa (MN), reflorestamento com espécies diversas (RF) e pastagem de Brachiaria brizhanta (PA) no município de Alta Floresta-MT.

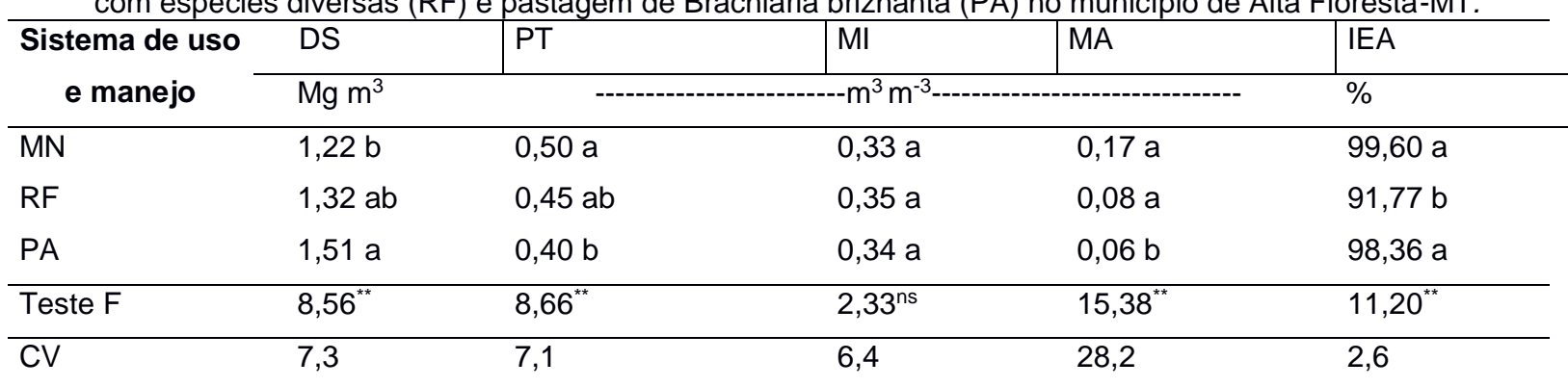

NS não significativo; ${ }^{*}$ significativo a $5 \%$ de probabilidade; ${ }^{* *}$ significativo a $1 \%$ de probabilidade. Médias seguidas de mesma letra na coluna não diferem entre si pelo teste de Tukey a 5\% de probabilidade. DS: densidade do solo; PT: porosidade total; MI: microporosidade; MA macroporosidade; IEA: índice de estabilidade de agregados.

\section{DISCUSSÃO}

Dentre os sistemas de uso e manejo do solo a pastagem incrementou a densidade do solo em 24 \% em comparação ao solo sob mata nativa (Tabela 1), o 
que indica uma redução da qualidade do solo causada pelo manejo incorreto da pastagem. A formação de camadas adensadas proporciona maior resistência física à expansão radicular (JIMENEZ et al., 2008), corroborando com trabalho de Reinert \&Reichert (2006) onde valores de Ds associados ao estado de compactação com alta probabilidade de oferecer riscos de restrição ao crescimento radicular situam-se em torno de 1,65 $\mathrm{g} \mathrm{cm}^{-3}$ para solos arenosos e $1,45 \mathrm{~g} \mathrm{~cm}^{-3}$ para solos argilosos, sendo que para a área de execução do trabalho o solo é classificado como LVADa.

O manejo incorreto está associado à ausência de preparo de solo, da correção da acidez, da adição de nutrientes, da taxa de lotação ou ainda ao controle de plantas invasoras durante os 36 anos de implantação.

Além destas, o adensamento do solo também pode ocorrer devido ao cultivo de capim com crescimento cespitoso, pela maior superfície do solo exposta ao pisoteio animal, pela idade da forragem, pela taxa de lotação e pela umidade do solo no momento do pastejo. (IMHOFF et al 2000). Portanto, pode-se inferir que, o solo sob Pastagem se encontra em um estágio de degradação física mais avançada do que o solo sob Reflorestamento. Já o solo sob Mata Nativa não apresenta valores de densidade acima do nível crítico.

A porosidade total do solo foi superior na mata nativa, uma vez que ambientes de preservação mantêm-se em equilíbrio físico-químico e biológico, realizando ciclagem de nutrientes da decomposição vegetal, mantendo níveis ideais aos padrões naturais, contribuindo para intensa e continua manutenção biótica refletindo na agregação e reestruturação do solo. A pastagem apresentou menor porosidade dentre os tratamentos, resultado este relacionado ao adensamento, que reduz os espaços porosos do solo em comparação ao solo nativo. BARBOSA et al. (2004) verificaram que o adensamento do solo reduziu a capacidade de armazenamento $e$ de infiltração de água no solo, devido à redução da porosidade total e porosidade de aeração, relacionadas à diminuição da matéria orgânica pela pastagem.

Para a variavel PT os valores foram inversos a DS, onde MN obteve maior resultado seguido pelo sistema RF e PA, se tornando mais compacto resultando no 
impedimento do desenvolvimento radicular (LIMA et al, 2013). Segundo Mazurana et al (2013) a MI recebe pouca influência da cobertura vegetal e o manejo aplicado sobre o solo, ao avaliar estes atributo em área com neem, capim elefante e outra área com capim brachiaria, concluindo que a maior influência se dá por condições intrinsecas do solo como matéria orgânica e textura, corroborando com sendo resultado semelhante encontrado neste trabalho onde não se encontrou diferença significativa para os sistemas de uso e manejo para essa variável. Na variáevel MA, a MN obteve melhor valor comparado com PA, resultado semelhante encontrado por Caetano et al.,(2013) onde encontrou que pastagens com elevada degradação, sem correção ou fertilização, mantidas sob pastejo contínuo tendem a reduzir o número de macroporos contribuindo para a degradação do solo.

A microporosidade não diferiu significativamente entre os tratamentos, pois não foi influenciada pelo manejo aplicado. Contudo, o solo sob todos os tratamentos apresentaram uma alta microporosidade o que favorece o armazenamento de água e o desenvolvimento das raízes finas que absorvem os nutrientes do solo, preferencialmente por meio de difusão (RUSSEL, 1981).

A baixa macroporosidade do solo sob pastagem e reflorestamento pode ser atribuída ao rearranjamento das partículas que sofreram adensamento pelo manejo imposto, essa alteração é agravada pelo pisoteio animal e pela falta de práticas conservacionistas, levando a um declínio nas atividades químicas e biológicas do solo, que afeta a reestruturação e a agregação das partículas (CARNEIRO et al., 2017 JORGE et al., 2012), uma vez que a densidade reduziu a porosidade total e a macroporosidade na área de pastagem.

A mata nativa e a pastagem proporcionaram os maiores valores de índice de estabilidade de agregados em comparação ao reflorestamento. Este resultado pode ser atribuído ao desenvolvimento do sistema radicular da floresta nativa nas camadas mais superficiais, o que contribuem para a estabilidade do solo e a manutenção da matéria orgânica, sendo determinante na cimentação dos agregados. Por outro lado, a agregação do solo sob pastagem pode ser atribuído ao 
adensamento do solo dado pela falta de práticas conservacionistas e de manejo adequado.

\section{CONCLUSÕES}

A elevada macroporosidade do solo sob mata nativa pode estar relacionada á ação do sistema radicular proporcionado pela exuberante vegetação, aos canais (bioporos) resultantes da decomposição e renovação das raízes, a intensa atividade biológica da mesofauna, aos elevados teores de matéria orgânica e as boas propriedades de agregação que este ambiente naturalmente apresenta (WENDLING et al., 2012; MATIAS et al., 2009).

A Microporosidade não diferiu significativamente entre os 3 tipos de cobertura do solo, mantendo-se em menor proporção quanto a quantificação.

A baixa Macroporosidade observada na Pastagem indica adensamento do solo em função do manejo adotado e poucas práticas de melhoria, no Reflorestamento indica início de recuperação do sistema.

Referente ao Índice de Estabilidade de Agregados, não foi observado diferença significativa quanto à quantidade de agregados retidos nas peneiras, com abertura de $0,25 \mathrm{~mm}$. Os sistemas de cultivo e manejo dos solos estudados promoveram alterações nas propriedades físicas, onde a utilização inadequada e a falta de práticas de manejo tem efeito prejudicial e cumulativo na estrutura do solo, contribuindo para diferentes formas de ocorrência de degradação.

\section{AGRADECIMENTOS}

Ao senhor Ércio Luedke por disponibilizar sua propriedade para a realização deste trabalho. 


\section{REFERÊNCIAS}

BARBOSA, G.M.C.; TAVARES FILHO, J.; FONSECA, I.C.B. Condutividade hidráulica saturada e não saturada de Latossolo Vermelho eutroférrico tratado com lodo de esgoto. Revista Brasileira de Ciência do Solo, Viçosa, v.28, n.2, p.403-407, 2004.

CAEtano, O. J.; Verginassi, A.; ASSIS, R. C. P.; CARNeIRO, C. A. M.;PAULINO, B. H. Indicadores de qualidade de um latossolo vermelho sob diferentessistemas de uso e manejo. Global Science Technology, v. 06, n. 01, p.2639, 2013. Disponível em: HTTP://DX.DOI.ORG/10.14688/1984-3801.V06N01A03

CARNEIRO, M.A.C.; SOUZA, E.D.; REIS, E.F.; PEREIRA, H.S. \& AZEVEDO, W.R. Atributos físicos, químicos e biológicos de solo de Cerrado sob diferentes sistemas de uso e manejo. Revista Brasileira de Ciência do Solo, Viçosa, v. 33; p. 147-157, 2009.

CARNEIRO, S. P. Qualidade de um Latossolo Vermelho sob diferentes tipos de usos e manejos em área do cerrado. 2010. 125p. Dissertação (Mestrado em geografia) Universidade Federal de Minas Gerais. Instituto de Geociências, Belo Horizonte, 2010.

EMPRESA BRASILEIRA DE PESQUISA AGROPECUÁRIA-EMBRAPA. Manual de métodos de análise de solo. 2 ed. Rio de Janeiro: Embrapa-CNPS, 1997. 212p.

EMPRESA BRASILEIRA DE PESQUISA AGROPECUÁRIA - EMBRAPA. Centro Nacional de Pesquisa de Solos. Manual de métodos de análise de solo. 2. ed. revista. Rio de Janeiro, 2011. p.225

EMPRESA BRASILEIRA DE PESQUISA AGROPECUÁRIA - EMBRAPA. Manual de métodos de análise de solo. 2.ed. Rio de Janeiro: Embrapa Solos, 2011. 230p.

FERREIRA, D. F. SISVAR: um programa para análise e ensino de estatística. Revista Symposium, Boa Vista, v. 6, p. 36-41, 2008.

https://pt.climate-data.org/location/4078/: acessado em 26/12/2017 21:09 pm. 
IMHOFF, S.; SILVA, A. P.; TORMENA, C. A. Aplicações da curva de resistência no controle da qualidade física de um solo sob pastagem. Pesquisa Agropecuária Brasileira, v.35, n.7, p.1493-1500, 2000.

INGARAMO, O. E. Indicadores físicos de la degradación del suelo. 2003. 298p. Tese (Doutorado) - Universidade da Coruña, La Coruña. 2003

JIMENEZ, R. L.; GONÇALVES, W. G.; ARAÚJO FILHO, J. V.; ASSIS, R. L.; PIRES, F. R.; SILVA, G. P. Crescimento de plantas de cobertura sob diferentes níveis de compactação em um Latossolo Vermelho. Revista Brasileira de Engenharia Agrícola e Ambiental, Campina Grande, v. 12, n. 2, p. 116-121, 2008.

JORGE, R. F.; ALMEIDA, C. X.; BORGES, E. N.; PASSOS, R. R. Distribuição de poros e densidade de latossolos submetidos a diferentes sistemas de uso e manejo. Bioscience Journal, Uberlândia, v. 28, n. 1, p159-169, 2012.

KEMPER, W.D. \& W.S. CHEPIL. Size distribution of aggregates. In: BLACK, C.A., ed. Methods of soil analysis. Madison, American Society of Agronomy, 1965. p.499510.

KEMPER, W.D. Aggregate stability. In: BLACK, C.A., ed. Methods of soil analysis. Madison, American Society of Agronomy, 1965. p.511-519.

KIEHL, E. J. Manual de Edafologia: relações solo-planta. São Paulo: Ceres, 1979. $262 \mathrm{p}$.

KLEIN, V. A.; CÂMARA, R. K. Rendimento da soja e intervalo hídrico ótimo em Latossolo vermelho sob plantio direto escarificado. Revista Brasileira de Ciência do Solo, v.31, p.221-227, 2007.

LIMA, H.N. Gênese, química, mineralogia e micromorfologia de solos da Amazônia Ocidental. 2001. 176p. Tese (Doutorado em solos e nutrição de plantas), Universidade Federal de Viçosa, 2001.

LIMA, A. M. I.; ARAÚJO, C. M. de.; BARBOSA, S. R. Avaliação das propriedadesfísicas do solo em sistemas silvipastoris, região centro norte, estado do 
Piauí. Agropecuária Cientifica no Semiárido, v.9, n.1, p.117-124, 2013. Disponível em: DOI:http://dx.doi.org/10.30969/acsa.v9i1.252

LLANILLO, R. F.; GUIMARÃES, M. F.; FILHO, J. T. Morfologia e propriedades Físicas de solo segundo sistemas de manejo em culturas anuais. Revista Brasileira de Engenharia Agrícola e Ambiental, Campina Grande, v. 17, n. 5, p. 524-530, 2013.

LOURENTE, E. R. P.; MERCANTE, F M.; ALOVISI, A. M. T.; GOMES, C. F.; GASPARINI, A. S.; NUNES; C. M. Atributos microbiológicos, químicos e físicos de solo sob diferentes sistemas de manejo e condições de cerrado. Pesquisa Agropecuária Tropical, Goiânia, v. 41, n. 1, p. 20-28, 2011.

MAZURANA, M.; FINK, R. J.; SILVEIRA, H. V. da.; LEVIEN, R.; ZULPO, L.;BREZOLIN, D. Propriedades físicas do solo e crescimento de raízes de milho em umArgissolos vermelho sobtráfego controlado de máquinas. Revista Brasileira de Ciência do Solo, v.36, n.5, p.1185-1195, 2013. Disponível em:http://dx.doi.org/10.1590/S0100-06832013000500008.

MAZZA, J. A.; VITTI, G. C.; PEREIRA, H. S.; MENEZES, G. M.; TAGLIARINI, C. H. Influência da compactação no desenvolvimento radicular de citrus: sugestão de método de avaliação e recomendação de manejo. Laranja, Cordeirópolis, v.15, n. 2, p.251-262, 1994.

NEVES, J. A. F. Avaliação da qualidade física de solos em pastagens degradadas da Amazônia. 2005. 65p. Dissertação (Mestrado em Solos e nutrição de plantas) Escola Superior de Agricultura "Luiz de Queiroz". Piracicaba 2005.

OLIVEIRA, G. C.; DIAS JUNIOR, M. S.; RESCK, D.V.S.; CURI, N. Alterações estruturais e comportamento compressivo de um Latossolo Vermelho Distrófico argiloso sob diferentes sistemas de uso e manejo. Pesquisa Agropecuária Brasileira, Brasília, v. 38, n. 2, p.291-299, 2003.

OSTERTAG, R. Effects of nitrogen and phosphorus availability on fine root dynamics in Hawaiian montane forests. Ecology, Washington, v. 82, n. 2, p. 485-499, 2001. 
REINERT, D.J. \& REICHERT, J.M. Propriedades físicas do solo. Santa Maria, Universidade Federal Santa Maria, 2006. 18p. Disponível em: <https://www.agro.ufg.br/up/68/o/An_lise_da_zona_n_o_saturada_do_solo_texto.p df> Acesso em: 27 fev. 2019.

RUSSEL, R.S. Plant root systems - Their function and interaction with the soil. In: SYMPOSIUM ON THE SOIL / ROOT SYSTEM, 1981, Londrina. Proceedings. Londrina, Instituto Agronômico do Paraná, 1981. p.3-20

VALLADARES, G. S. BATISTELLA, M. PEREIRA, M. G. Alterações ocorridas pelo manejo em Latossolo, Rondônia, Amazônia Brasileira. Bragantia, v. 70, n. 3, p.631637, 2011. Disponível em: < http://www.scielo.br/pdf/brag/v70n3/a19v70n3.pdf>.

WENDLING, B.; FREITAS, I. C. V.; OLIVEIRA, R. C.; BABATA, M. M.; BORGES, E. N. Densidade, agregação e porosidade do solo em áreas de Conversão do cerrado em floresta de pinus, pastagem e Plantio direto. Bioscience Journal, Uberlândia, v.28, p.256-265, 2012. 